\title{
New pedagogical configurations for traditional learning tools: a proposal
}

\author{
Raimúndez-Urrutia, Elena; Azzato Sordo, Mariella \\ Universidad Simón Bolívar, Caracas, Venezuela
}

\begin{abstract}
Digital technologies have changed the world dramatically and, as a consequence, higher education is undergoing significant teaching and learning transformations based on their use. The need to plan and produce disruptive innovations for traditional learning tools brings a challenge in this sense. One of these modern pedagogical perspectives is the use of transmedia storytelling in education, which has given a new configuration to instructional tools and have changed their forms and educational function. We present a proposal of specialized vocabulary in reproductive biology of plants using the principles of transmedia storytelling. The design of an educational transmedia artifact for the particular terminological entry of the term «polinizador» is shown to illustrate the proposed structure for the vocabulary. This artifact is constituted by diverse resources made with the use of different media and is based on the use of tags linked to each resource, which allow interactive navigation between them, structuring the storytelling about the selected term. Each resource adds particular information on the definition of the term, so that the student can obtain the answer he needs. Transmedia storytelling allows the students' interaction with resources in a way consistent with their own interests, making them the center of their learning.
\end{abstract}

Keywords: Transmedia storytelling; educational artifact; specialized vocabulary; disruptive materials; knowledge space. 


\section{Introduction}

The advent of digital technologies has changed the world dramatically and higher education is undergoing significant transformations as a result of technological innovations. The way higher education is taught and students learn is changing and this change will be enhanced by the integration of new tools and pedagogies that engage students. Newest ideas focus on the production of disruptive materials that comply with student-centered pedagogy (Adell \& Castañeda, 2012; Fullan \& Langworthy, 2014). In this sense, new pedagogies emerge around the use of ICTs in education and seek to exploit their full communicative, informational, collaborative, interactive, creative and innovative potential within the framework of a new culture of learning (Veletsianos, 2010; Adell \& Castañeda, 2012).

In the midst of all these transformations, education has begun to take into account new communicative ways such as transmedia storytelling. This concept was introduced by Henry Jenkins in the world of communication in 2003 and since then we have switched from using terms like «multimedia» and «interactivity» to terms like «transmedia» and «convergence» (Jenkins, 2008; Scolari, 2013). Now, each media contributes part of the story and it is the «convergence» of the information contained in each one that creates the whole; each media is used «to do the best it can do» (Scolari, 2013) using different systems of meaning and language: verbal, iconic, audiovisual, interactive, etc. The «culture of convergence» is characterized by «liquid» contents that «flow» through multiple media and by the migration of audiences, who are no longer «loyal» to a particular media but to their own informational interest (Jenkins, 2008; Campalans, 2015).

Thus, in higher education context, transmedia storytelling has given a new visual and audiovisual configuration to the instructional image, which has changed its forms and its educational function with the evolution of digital technologies (Azzato 2015a). The contents developed in different media allow to generate «educational artifacts» (Azzato 2015a) that offer other possibilities for reading and understanding these contents, because transmedia storytelling has no order or direction, which allows the student to interact with its components in a personal way to build each one's meaningful learning (Azzato 2015b; Campalans 2015). Knowledge is produced through multiple interconnections and in different ways in each student, according to their own interests and skills in the digital world (Azzato 2015b; Campalans 2015). Thus, in knowledge built on a transmedia basis, students' understanding and involvement with respect to content may be enhanced by the diversity of media used.

According to these modern pedagogical perspectives, the need to plan and produce new learning tools in higher education is mandatory and disruptive configurations for traditional educational tools bring a challenge in this sense; dictionaries, or vocabularies in the case of terminologies, are one of these cases. In this work, we present a proposal of designing a 
specialized vocabulary using transmedia storytelling; the design of an educational transmedia artifact for the particular terminological entry of a term is shown to illustrate the proposed structure for the vocabulary.

\section{Design of the educational transmedia artifacts}

Each educational artifact for terms in the vocabulary will be designed using the principles of transmedia storytelling: 1) Existence of a global message for each artifact, that will be the particular definition of the term. 3) Use of various media, devices or languages to design different resources in order to show with each of them one independent story, which converges with the other resources to articulate the global message; that is, the stories narrated by each one of the developed resources must add up for the understanding of the definition of the term; each resource will be done with different applications and will include videos, sounds, texts, images, etc. 3) Finally, and perhaps the most important, each resource developed to be part of the educational transmedia artifact should allow students to make further progresses in the search for new information according to their interests, because each resource should be open for student's active participation.

To explain the design of one educational artifact, a terminological article, we will use as example the term «polinizador» from the Specialized vocabulary in Reproductive biology of plants (Raimúndez-Urrutia, 2012).

\subsection{Terminological article for the term «polinizador»}

Information contained in the terminological article for the term «polinizador» is shown in Figure 1.

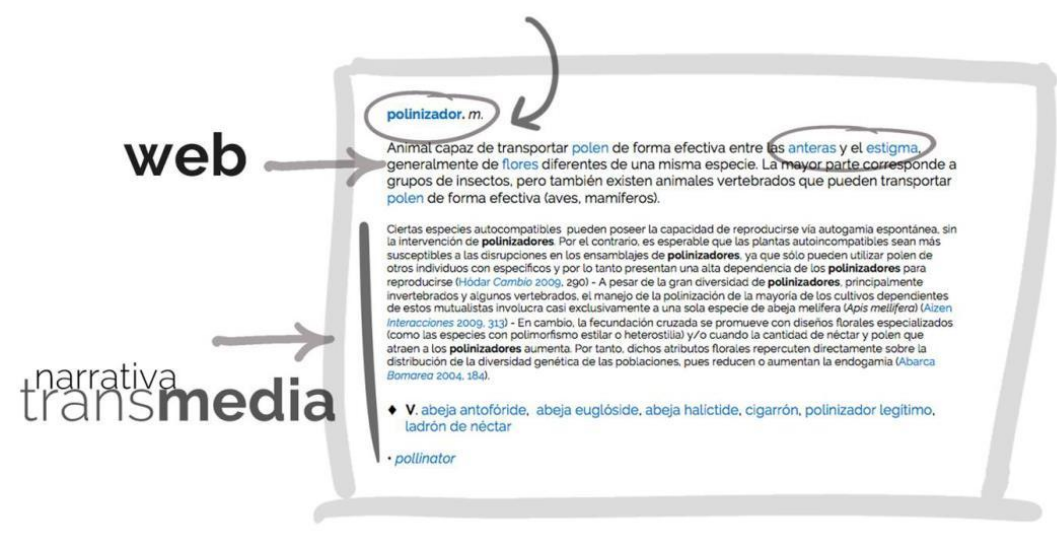

Figure 1. Elements of the terminological article for the term «polinizador». 
The terminological article consists of three main parts: term, definition and complementary elements. Both the term and the definition will appear on the website VocEs (https://www.voces.proyectos.usb.ve/es), from which there will be access to all the terms in this vocabulary. The term will be accompanied by its grammatical gender and will be the link that connects the term page in the website with the transmedia artifact. If the definition includes other terms that are also collected in the vocabulary, these will be links to their corresponding page on VocEs and, hence, to their corresponding transmedia artifact. Finally, the complementary information will form part of the educational transmedia artifact; it has texts in which the use context of the term can be verified, related terms that will also be links to their pages on the website, and the English term, linking to texts in this language and which will allow also the codification of texts in English.

\subsection{Educational transmedia artifact design}

The educational transmedia artifact designed for «polinizador» is shown in Figure 2.

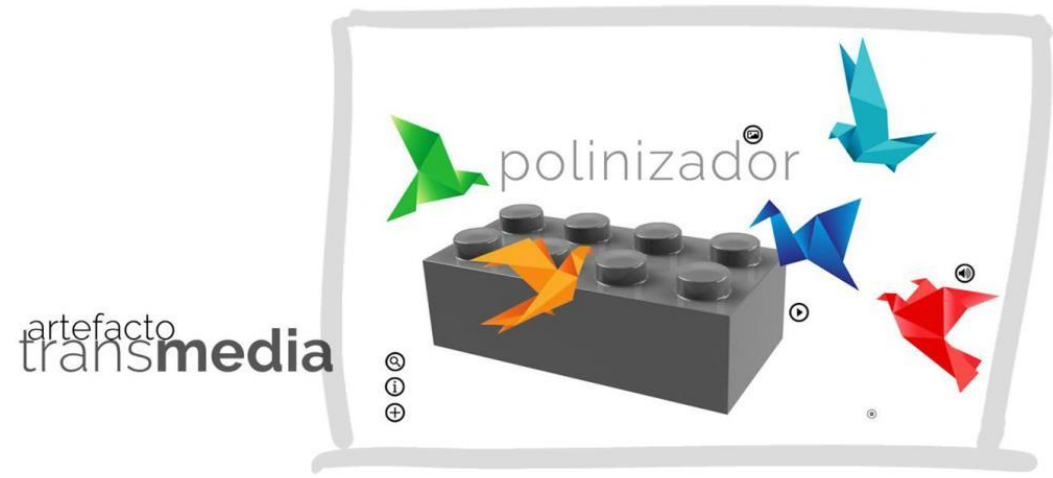

Figure 2. Educational transmedia artifact for the term «polinizador» (http://www.genial.ly/5765847ffo95e647d8dc8122/polinizador)

The educational artifact was created using Geanily's online software from Genially web S.L. (https://www.genial.ly/es) which allows the development of interactive and animated content. It is based on the use of labels or tags linked to different media (rich media tags), which allow interactive navigation between the media that will structure the storytelling about the selected term. The tags link to: 


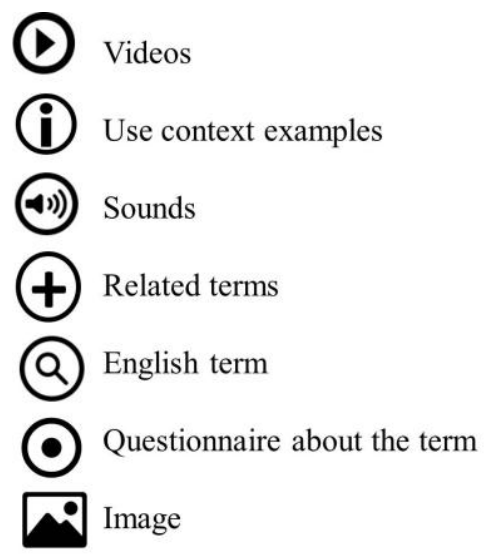

Each of these tags has particular characteristics depending on the media and the platform used to transmit the information, and all of them as a whole make up the «knowledge space» (Azzato, 2015b) for the term, through the interactions that the student establishes with the resources and among them. The student will be able to navigate between resources according to his criterion or interest, so as to obtain the necessary information to construct the answer to the learning question. The digital educational resources for each of the terminological articles may be developed by teachers themselves, although other open digital sources available on the internet, as a corpus of educational resources, may also be used.

Finally, all the educational transmedia artifacts designed for specialized terms in this vocabulary will be joined in the site VocEs: Vocabularios de Especialidad under the title Vocabulario de especialidad en Biología reproductiva de plantas. This vocabulary, in turn, will be part of an entire educational transmedia supra-artifact that will be developed for the subject Biología reproductiva de angiospermas. In fact, the educational supra-artifact would begin the storytelling in the classroom, face-to-face with the students, which is where the theory supporting the vocabulary is taught. As a whole, the site VocEs looks to collect specialty vocabularies for all teaching subjects in the Universidad Simón Bolívar, as another level of educational transmedia supra-artifact. 


\section{Discussion}

The traditional educational tools, such as dictionaries or vocabularies of specialty, must adapt to existing demands in terms of teaching and learning in the new formal and nonformal spaces in higher education. This arises the need to plan and produce new learning and communication tools that can be used in the different portable devices with which students are currently accessing the information. However, the new pedagogical approach cannot simply be a substitution of technologies, but must be based on a new vision of learning (Adell \& Castañeda, 2012; Fullan \& Langworthy, 2014). In this sense, transmedia storytelling, as a new pedagogical approach, allow us to develop a disruptive configuration for a specialty vocabulary used in higher education, which will be web-based to create a more attractive and complete tool for today's students.

The contribution of emerging technologies should allow a different interaction between students and content (Adell \& Castañeda, 2012; Fullan \& Langworthy, 2014; Campalans 2015). With them, the teacher can create expectations about new and interesting things that students must discover, assimilate and integrate to actively build their learning. In this proposal, learning starts in the classroom, but then expands through all new media available, among which are educational artifacts designed for the terms of the specialty. Therefore, they should be intercommunicative, face-to-face and virtual spaces that open up in the hyperconnected world to offer areas of dialogic learning, intercultural socialization and collective knowledge construction (Azzato 2015a).

Tagged images will be part of the learning spaces for the terms of specialty. Tags constitute the space of knowledge and the knowledge will be shaped by the assembly that the student makes of each of the contents that have been tagged multimodally (Azzato 2015a; b). New digital applications for the management of images allow the incorporation of tags with which different resources, developed with and to different media, are identify. The educational transmedia artifact will be materialized from a tagged visual image, which gives form, instructional function and social meaning to the educational content, the terms, from visual and audiovisual narratives represented in different media and platforms that will perform, through the exchange and interaction in different social contexts, the construction of knowledge (Azzato 2015a). The tags help the student to identify the type of resource and to select those most meaningful to him and, thus, to begin the construction of the story that will allow him to understand the corresponding term.

In this way, an active attitude of the student, analyzing and selecting the resources that would make him know the message, will be necessary because he will be able to move between resources according to his affinity for them. This attitude must also be translated into feedback to those stories and to a relationship with other students who are also consuming that contents. This instructional methodology promotes the development of a 
"transmedia thinking" (Azzato 2015b), which, as a cognitive tool, will allow the student to develop skills to decode, codify, organize, structure and relate concepts, elaborating their own visual speeches on a certain content (Azzato 2015a; b).

Connection to information and knowledge networks will be another social fact in the scenario of the convergence culture (Azzato 2015b; Campalans 2015) that can be promoted by transmedia storytelling. In this way, these vocabularies will have two approaches: the lexicographical, traditional, approach and a playful, connectivist approach that will allow students to elaborate their own visual speeches and, thus, their knowledge about the terms, according to their own mental processes of learning, using the new learning approaches and digital media.

\section{Conclusion}

The project VocEs proposes a new model of lexicographic tool for higher education, in which information and communication technologies are used along with new educational approaches. These new approaches take into account users, i.e. students and their characteristics, not only in terms of new forms of learning, but also in the use of mobile devices with which they access information. One advantage that this proposal may have is that each educational transmedia artifact corresponding to a terminological article of the vocabulary can contain as much information as is necessary to achieve the definition of the term, since, in addition, links to the internet make available a corpus of visual or audiovisual resources that could form the educational artifacts developed for the terms. Images, along with the tags they include and the associated resources, represent educational transmedia artifacts that can be in turn, linked with other educational artifacts to construct supra-artifacts, i.e. a no limits knowledge space. 


\section{References}

Adell, J., \& Castañeda, L.J. (2012). Tecnologías emergentes, ¿pedagogías emergentes? In J. Hernández, M. Pennesi, D. Sobrino \& A. Vázquez (Coord.), Tendencias emergentes en educación con TIC (pp. 13-32). Barcelona: Asociación Espiral, Educación y Tecnología. Retrieved from http://hdl.handle.net/10201/29916.

Azzato, M. (2015a). Artefactos educativos. Retrieved from http://mazzato.dsm.usb.ve/web/es/node/41.

Azzato, M. (2015b). Transmedia mind. Retrieved from http://mazzato.dsm.usb.ve/web/sites/default/files/pensamiento_transmedia.pdf.

Campalans, C. (2015). Docencia/aprendizaje transmedia: una experiencia. Razón y Palabra, 89, 89-102. Retrieved from http://www.revistarazonypalabra.org/index.php/ryp/article/viewFile/211/252.

Fullan, M., \& Langworthy, M. (2014). A rich seam. How new pedagogies find deep learning. London: Pearson. Retrieved from http://hornepaynehigh.adsb.on.ca/uploads/info/listings/3897.Rich_Seam_web.pdf.

Jenkins, H. (2008). Convergence Culture. La cultura de la convergencia de los medios de comunicación. Barcelona: Editorial Paidós Ibérica. Retrieved from https://stbngtrrz.files.wordpress.com/2012/10/jenkins-henry-convergence-culture.pdf.

Raimúndez-Urrutia, E. (2012). Propuesta para un vocabulario de especialidad en biología reproductiva de las plantas. Revista de Lexicografía, XVIII, 141-157. Retrieved from http://hdl.handle.net/2183/12134.

Scolari, C. (2013). Narrativas transmedia: Cuando todos los medios cuentan. Barcelona: Deusto S.A. Ediciones.

Veletsianos, G. (2010). A definition of emerging technologies for education. In G. Veletsianos (Ed.), Emerging technologies in distance education (pp. 3-22). Athabasca, CA: Athabasca University Press. 